JMLC

21,3

\section{6}

\title{
Time required to move cash through slot machines
}

\author{
Karen Kelly \\ Exiger, Vancouver, Canada \\ Carl James Schwarz \\ Simon Fraser University, Burnaby, Canada \\ Ricardo Gomez \\ Exiger, Miami, Florida, USA, and \\ Kim Marsh \\ Exiger, Vancouver, Canada
}

\begin{abstract}
Purpose - The purpose of this paper is to present an empirical study on the time needed to load and disburse cash using bill validators on slot machines and stand-alone cash dispensers in casinos in British Columbia under a Ticket In Ticket Out (TITO) system.

Design/methodology/approach - Testing took place over two days, using 18 machines. The results were extrapolated to estimate the approximate time required to process $\$ 1,000,000$ with different average bill amounts in the cash mix and three different bill validator machines in common use. The average value per bill using the cash mix used by the public in the casino was $\$ 33.11$ [standard error (SE) \$2.11].

Findings - The mean time/accepted note ranged from 4.12 to $9.65 \mathrm{~s}$, depending on bill validator type. This implies that the time needed to load $\$ 1,000,000$ onto credit slips using bill validators on slot machines ranges from 35 to $81 \mathrm{~h}$, excluding rest breaks and other breaks. The time needed to redeem $\$ 1,000,000$ is estimated to be $3 \mathrm{~h}$.

Practical/implications - The implications of these finding for illicit actors to successfully launder large amounts of cash are discussed. Given the time needed to physically handle the cash, and other control systems currently in use in casinos in British Columbia, processing large amounts of cash using bill validators on slot machines would require a highly organized team that would find it difficult to elude detection.

Originality/value - The trial results provide a baseline estimate to be used going forward when investigating or proposing money laundering methodologies that include slot machines.
\end{abstract}

Keywords Money laundering, Casino, Bill validator, Refining, Slot machine,

Ticket in ticket out (TITO)

Paper type Research paper

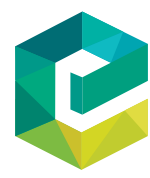

Journal of Money Laundering Control

Vol. 21 No. 3, 2018

pp. $376-384$

pp. 376-384

1368-5201

DOI 10.1108/JMLC-09-2017-0049

\section{Introduction}

\subsection{Background}

Casinos in Canada are subject to reporting and anti-money laundering (AML) program requirements as set forth in the Proceeds of Crime (Money Laundering) and Terrorist

(C) Karen Kelly, Carl James Schwarz, Ricardo Gomez and Kim Marsh. This article is published under the Creative Commons Attribution (CC BY 4.0) licence. Anyone may reproduce, distribute, translate and create derivative works of this article (for both commercial and non-commercial purposes), subject to full attribution to the original publication and authors. The full terms of this licence may be seen at http://creativecommons.org/licences/by/4.0/legalcode 
Financing Act (PCMLTFA, 2000). This includes obligations to implement and carry out Know Your Customer procedures, report large cash transactions of $\$ 10,000$ or more and report suspicious transactions and attempted suspicious transactions (Duhaime, 2016).

The Financial Action Task Force (FATF) has recognized in its most recent Mutual Evaluation Report (2016) that Canadian casinos represent a relatively high level of AML compliance as compared to other designated non-financial business and professions (DNFBPs) and have a good understanding of money laundering and terrorist financing risks and of the most frequent money laundering typologies in their sector. Casinos were described as being adequately aware of their reporting obligations under the legislation; suspicious transaction and threshold-based reporting levels were reported to be very low in all Canadian DNFBPs with the noted exception of casinos (FATF, 2016).

\subsection{Perceived risk of the casino industry}

As cash-intensive enterprises, casinos represent a higher risk for money laundering and terrorist financing (NAICS, 2014).

Following negative media reports in 2011, the British Columbia Minister of Public Safety and Solicitor General ordered a review of AML methods used in gaming establishments across the province. While the review found that, overall, the AML program elements in place were appropriate and robust, cash transactions were identified as a vulnerability because of anonymity associated with cash buy-ins (Province of British Columbia, 2011).

Several recent cases reported in the media in Canada refer to illegal actors laundering money through casinos and in some cases specifically through the use of slot machines (Lee and Shaw, 2014; Smyth, 2016).

\subsection{Are slot machines an adequate tool for money laundering?}

Slot machines in British Columbia require the player to load a credit slip (Ticket In Ticket Out system [TITO]) by placing currency into cash validators attached to the machine. A player may only load the value on a single machine to a particular limit (e.g. \$2,500). A player may use the stored value on a ticket slip to transfer to another machine, and losses and winnings are deducted/added to the tickets. At any point, the player may take the Ticket Out and redeem cash from a cash dispenser in the casino or at the cash cage.

Tickets cannot be used in other casinos or be redeemed in any other way, i.e. prepaid cards; however, the tickets may be attractive for illicit activities in place of actual currency and because of the anonymous nature of loading the tickets and of redeeming cash. The Financial Transactions and Reports Analysis Centre of Canada (FINTRAC) previously reported that the TITO system may be vulnerable because of anonymity especially in combination with automated redemption terminals (FINTRAC, 2009).

The logistics of using slot machines to process and (ultimately) launder cash have not been reported in detail. In particular, the time required to physically input a large amount of cash in a live casino scenario has not been empirically tested or reported on. Therefore, before speculating on possible money laundering methods incorporating slot machines, it is necessary to consider the time investment.

Would the time required to input very large amounts of money into slot machines act as a deterrent to illicit actors? This report summarizes an empirical study on the time needed to load and disburse cash using bill validators and dispensers in casinos in British Columbia. The results are extrapolated to estimate the approximate time required to process $\$ 1,000,000$. 
JMLC 21,3

\section{Materials and methods}

All casinos in British Columbia are managed by the British Columbia Lottery Corporation (BCLC), which is a Crown corporation. The BCLC confirmed to the research team that all slot machines in use in casinos in the province currently include one of three types of bill validators - MEI SC Advance, MEI CashFlow (SC83) and UBA (UBA-1x-SS series by JCM) and gave the research team access to data outlining the breakdown of slot machine and validator types across the province. The team determined the appropriate methodology based on the data provided, independent of the BCLC, and the BCLC then arranged testing sites, days and currency as requested.

The breakdown of bill validator types in individual casinos varies. All bill validators accept Canadian currency notes in any denominations inserted in any of the four possible orientations. Note that coins for $\$ 1$ and $\$ 2$ are not accepted by the bill validators. The bill validators occasionally reject a note because the player did not insert it properly, the bill was very worn or the bill was folded. The credit limit on the machines varies, with the maximum available limit at $\$ 2,500$ on a single machine.

Software updates are carried out by engineers across all machines, validators and casinos as available and required. These include updates to accept new editions of currency as they enter circulation. Province-wide updates ensure a slot machine and bill validator at a casino in Northern British Columbia is running identical software and updates as a machine in the Lower Mainland.

This empirical study took place over two days, with seven team members (alternating as feeders and recorders) using 18 machines. Testing occurred at the River Rock Casino in Richmond, British Columbia, a casino in which all three bill validator types are in active use. On each day, casino management "reserved" machines with validators of each type with a $\$ 2,500$ credit limit (the maximum available) that were in close proximity of each other. Management provided bundles of notes that were not sorted by denomination and represented the mix of denominations typically used by players on the slot machines.

For each timed trial, one member of the team fed notes into the bill validator while a second member recorded the number of notes attempted, the number of notes accepted and the number of notes rejected by the bill validator. Bills were fed to the bill validator until the machine refused to accept any more notes because the credit amount was at $\$ 2,500$ or the new note would have exceeded $\$ 2,500$. At this point, the Ticket Out was printed for the full credit. The time when the trial started and ended was recorded by the observer on a stopwatch. No actual gambling took place.

Team members switched positions (i.e. the observer became the feeder and vice versa) and did another trial with a different set of notes. Teams also switched between machines. The experiment attempted to balance tests across machines but this was not always possible.

The estimated time/accepted bill was computed for each machine type $(v)$ using a ratioof-means estimator (Cochran, 1977):

$$
\bar{T}_{v}=\frac{\sum \text { Time }}{\sum \text { Accepted Bills }}
$$

where the summation signs are taken over all trials for that bill validator type.

The average number of accepted bills/dollar credited is computed in a similar fashion but pooled over all trials of all validator types because the note distribution is expected to be the same in all trials for all machines: 


$$
\bar{A}=\frac{\sum \text { Accepted Bills }}{\sum \text { Credit Limits }}
$$

The predicted time to process $\$ 1,000,000$ for a bill validator type is then found as:

$$
L_{v ; 1,000,000}=1,000,000 \times \bar{A} \times \bar{T}_{v}
$$

All standard errors were computed using bootstrapping. Approximate 95 per cent confidence intervals for estimates can be computed using the estimate $\pm 2 S E$ large sample approximation.

\section{Results}

A summary of the raw data for the timed trials to load the credit value in the slot machines is presented in Table I and Figure 1. In three trials, the maximum credit limit was $\$ 500$ rather than $\$ 2,500$, as casino staff had mistakenly set a single machine at the lower limit value; timed trial data was nonetheless collected from the three testing runs on this machine and included in the data for that bill validator type (MEI Cash Flow). There were no obvious outliers and there did not appear to be pattern among our testers where, for example, one tester was consistently slower than another tester.

The bundle of notes consisted of mostly $\$ 20$ denominations with fewer $\$ 50$ (or larger) and the occasional $\$ 10$ and $\$ 5$ denominations. The average number of bills/dollar credit limit $(\bar{A})$ was 0.030 [standard error (SE) 0.0016 ] corresponding to an average value per note of $1 / 0.030=\$ 33.11$ (SE $\$ 2.11$ ). Hence, a million dollars is represented by approximately $\$ 1,000,000 / \$ 33.11$ or 30,200 notes. This corresponds to a stack about $2.7 \mathrm{~m}$ tall [assuming an average thickness of 91 micrometers for the polymer notes (https:/en.wikipedia.org/wiki/ Frontier_Series)].

\begin{tabular}{llcccc}
\hline Tester & Validator type & Maximum credit allowed & No. of accepted bills & No. of rejected bills & Time (s) \\
\hline N.H. & MEI Advance & 2,500 & 92 & 2 & 528 \\
K.K. & MEI Advance & 2,500 & 112 & 1 & 488 \\
C.S. & MEI Advance & 2,500 & 90 & 4 & 344 \\
C.S. & MEI Advance & 2,500 & 73 & 6 & 361 \\
A.A. & MEI Advance & 2,500 & 84 & 3 & 288 \\
C.C. & MEI Advance & 2,500 & 49 & 0 & 155 \\
S.K. & MEI Advance & 2,500 & 68 & 2 & 238 \\
N.H. & MEI Advance & 2,500 & 78 & 1 & 258 \\
A.A. & MEI Cash Flow & 2,500 & 68 & 14 & 361 \\
C.C. & MEI Cash Flow & 500 & 24 & 3 & 137 \\
C.C. & MEI Cash Flow & 500 & 24 & 9 & 203 \\
C.C. & MEI Cash Flow & 500 & 19 & 0 & 94 \\
C.C. & MEI Cash Flow & 2,500 & 34 & 10 & 209 \\
A.A. & MEI Cash Flow & 2,500 & 67 & 21 & 366 \\
A.A. & MEI Cash Flow & 2,500 & 53 & 9 & 350 \\
C.C. & MEI Cash Flow & 2,500 & 97 & 13 & 266 \\
G.M. & UBA & 2,500 & 81 & 3 & 970 \\
S.K. & UBA & 2,500 & 94 & 18 & 949 \\
S.K. & UBA & 2,500 & 65 & 9 & 640 \\
N.H. & UBA & 2,500 & 92 & 11 & 705 \\
N.H. & UBA & UBA & 2,500 & 7 & 800 \\
S.K. & UBA & & Summary of data \\
from timed trials \\
\hline
\end{tabular}


JMLC

21,3

380

Figure 1.

Summary of results of timed trials

\section{Table II.}

Mean processing time/accepted note and the estimated time to process $\$ 1,000,000$ based on the observed distribution of note denominations corresponding to an average value per note of $\$ 33.11$ (SE \$2.11)

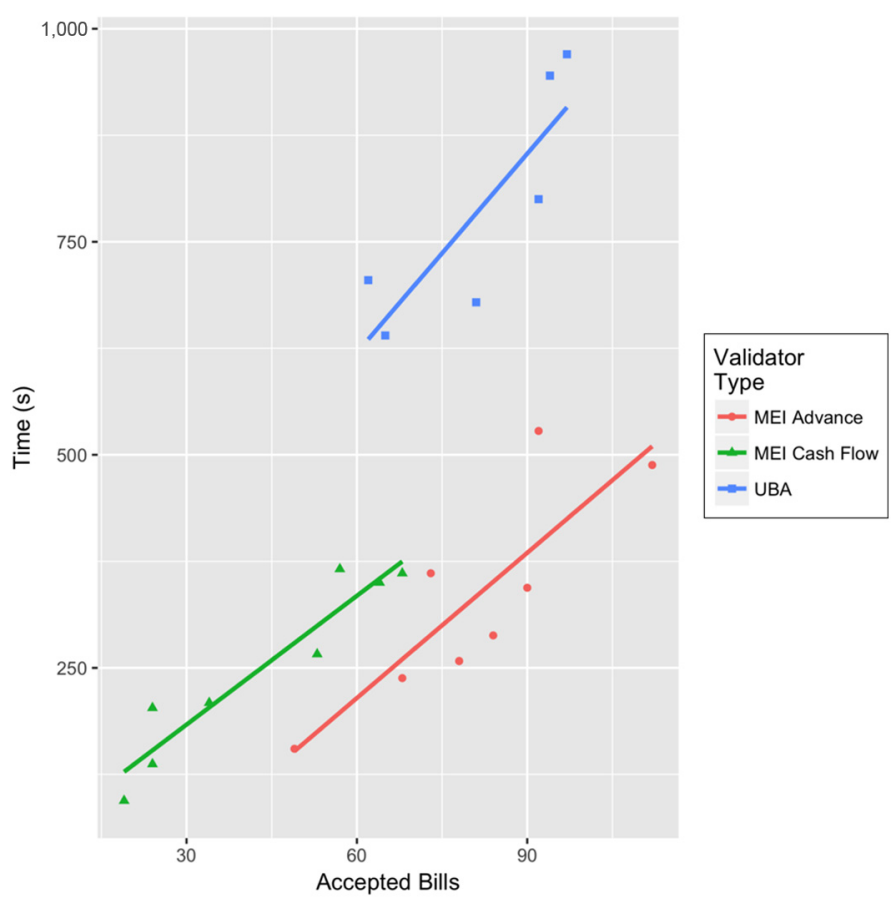

Note: The credit limit was $\$ 2,500$ for all but three trials

The summary of the mean processing time per note for each validator type and the approximate time needed to process $\$ 1,000,000$ is given in Table II. The processing time/ note for the UBA machines is approximately two times longer than for the two other machines. It would take about 40 uninterrupted $\mathrm{h}$ to process $\$ 1,000,000$ using the observed distribution of denominations in our trials for the MEI machines and about two times as long for the UBA machines. These values exclude rest breaks and set-up time.

A summary of the raw data for the time to redeem the credit slips is presented in Table III. It takes approximately $25 \mathrm{~s}$ to redeem a single Ticket Out for $\$ 2,500$, or approximately $3 \mathrm{~h}$ to redeem tickets totaling $\$ 1,000,000$.

\begin{tabular}{lcccc}
\hline & $\begin{array}{c}\text { Mean time/ } \\
\text { accepted note }(\mathrm{s})\end{array}$ & $\begin{array}{c}\text { SE (mean time/ } \\
\text { accepted note) (s) }\end{array}$ & $\begin{array}{c}\text { Estimated time to process } \\
\$ 1,000,000(\mathrm{~h})\end{array}$ & $\begin{array}{c}\text { SE (Estimated time to } \\
\text { process } \$ 1,000,000)(\mathrm{h})\end{array}$ \\
\hline MElidator type Advance & 4.12 & 0.32 & 35 & 4 \\
MEI Cash Flow & 5.79 & 0.33 & 49 & 4 \\
UBA & 9.65 & 0.42 & 81 & 5 \\
\hline
\end{tabular}




\section{Discussion}

\subsection{Processing large cash volumes through slot machines}

The estimated time to process $\$ 1,000,000$ represents the cumulative time at the bill validators. It is important to note that the time figure represents an ideal and uninterrupted scenario, excluding any other activities expected to occur in real life, including rest breaks, set-up, interaction with casino staff, conversation with any other individuals, moving between machines and actual gambling. Incorporation of even a few of these activities could conceivably double or triple the time required. It is unlikely that a single person would process this amount of currency in one continuous and uninterrupted session. It is possible that this processing could be divided among many individuals, each of which may spend only a small amount of time at a machine; however, interruptions and other activities such as gambling would still lengthen the total time required for each individual.

The input alone of cash into slot machines does not obscure the money's origin; a Ticket Out for inputted money does not give the holder any paper trail to claim another origin, such as jackpot winnings. However, Tickets Out could facilitate the refining of bills (converting a larger bundle of small denomination bills into larger denomination bills, which can be more easily transported) (FINTRAC, 2009). The hours invested by the individual or team to insert the money would represent only the first step if the player(s) had a desire to obscure the origin of funds.

Table IV presents the approximate time to process $\$ 1,000,000$ in notes set at specific values. To input that amount in $\$ 10$ notes into the MEI advance bill validator type (the fastest of the three types) would take approximately 114 continuous h; the estimated time would double for $\$ 5$ notes. Gambling, rest and interactions with others would increase the estimate significantly. These timeframes are relevant to the scenario described above, that of attempting to refine bills to larger denominations, as the player(s) would begin with smaller denomination bills.

\subsection{Mitigating controls}

It is important to note strategies used by the BCLC and service providers (casinos and community gaming centers) that would mitigate the type of refining activity described. All front-line and surveillance staff working in gaming facilities are required to undergo AML training that must be refreshed every two years. The most recent version of the course, completed through video training segments delivered online with a mandatory final test, includes detailed descriptions of suspicious and reportable behavior and transactions on the casino floor, as well as reporting thresholds for Large Cash Transaction Reports. Possible scenarios used as examples include players inserting large amounts of small denominations into slot machines, gambling very little and retrieving Tickets Out; players who appear to be exchanging tickets, chips or cash to cash out; or multiple players who are spread out yet appear to be connected or collaborating based on the observations of staff (BCLC, "BCLC Anti-Money Laundering (AML) for Casino and CGC", 2017). Suspicious behavior examples such as these, which are based on FINTRAC Guidelines (FINTRAC, 2017), are also outlined in detail in the BCLC AML Manual (BCLC, "BCLC AML Manual", 2017). 


\begin{tabular}{|c|c|c|c|c|c|c|}
\hline 21,3 & Validator type & $\begin{array}{c}\text { Average value/ } \\
\text { note }(\$)\end{array}$ & $\begin{array}{l}\text { Mean time/ } \\
\text { accepted } \\
\text { note (s) }\end{array}$ & $\begin{array}{c}\text { SE (mean time/ } \\
\text { accepted note) (s) }\end{array}$ & $\begin{array}{l}\text { Estimated } \\
\text { time to process } \\
\$ 1,000,000(\mathrm{~h})\end{array}$ & $\begin{array}{l}\text { SE (Estimated time } \\
\text { to process } \\
\$ 1,000,000)(\mathrm{h})\end{array}$ \\
\hline \multirow{5}{*}{382} & MEI Advance & 5 & 4.12 & 0.32 & 229 & 18 \\
\hline & MEI Advance & 10 & 4.12 & 0.32 & 114 & 9 \\
\hline & MEI Advance & 20 & 4.12 & 0.32 & 57 & 4 \\
\hline & MEI Advance & 50 & 4.12 & 0.32 & 23 & 2 \\
\hline & MEI Advance & 100 & 4.12 & 0.32 & 11 & 1 \\
\hline Table IV. & MEI Cash Flow & 5 & 5.79 & 0.33 & 322 & 18 \\
\hline Mean processing & MEI Cash Flow & 10 & 5.79 & 0.33 & 161 & 9 \\
\hline time/accepted note & MEI Cash Flow & 20 & 5.79 & 0.33 & 80 & 5 \\
\hline timelaccepted note & MEI Cash Flow & 50 & 5.79 & 0.33 & 32 & 2 \\
\hline and the estimated & MEI Cash Flow & 100 & 5.79 & 0.33 & 16 & 1 \\
\hline time to process & UBA & 5 & 9.65 & 0.42 & 536 & 23 \\
\hline$\$ 1,000,000$ based on & UBA & 10 & 9.65 & 0.42 & 268 & 12 \\
\hline lower and higher & UBA & 20 & 9.65 & 0.42 & 134 & 6 \\
\hline average note & UBA & 50 & 9.65 & 0.42 & 54 & 2 \\
\hline denominations & UBA & 100 & 9.65 & 0.42 & 27 & 1 \\
\hline
\end{tabular}

In addition to staff awareness and reporting, slot machines have embedded technology (Gaming Management System or GMS) that can be set to specific thresholds by BCLC to monitor for suspicious activity, including inserting cash but recording little to no play. When suspicious activity is detected based on the previously set thresholds, the GMS generates alerts to staff, including surveillance operators, triggering additional follow-up activity and monitoring (BCLC, "BCLC Slots Policy", 2017). According to BCLC staff, this technology is currently being tested (for ideal threshold settings) and rolled out incrementally in gaming facilities across the province.

\section{Conclusion}

The question posed for this experiment was if the time required to input very large amounts of money into slot machines would act as a deterrent to illicit actors. Does the inconvenience of committing more than $100 \mathrm{~h}$ to the input of smaller denomination bills rule out slot machines as a tool for money laundering?

While it may be inconvenient for a single individual, it is conceivable that an organized criminal group could task a team of individuals with inputting cash to both speed up the overall timeline and lessen the likelihood of detection or suspicion by casino staff. A team of 20 people could each spend an hour per day over five days at five different local casinos. This type of team-refining activity can be included in money laundering typologies for casinos. Red flags would include individuals frequently appearing across multiple casinos in the same area with significant cash amounts and redeeming a large percentage of the inputted cash back from redemption machines. This type of activity would be challenging to identify because of the anonymity associated with cash buy-ins unless the same individuals were used on a regular basis, facilities had an adequate number of slot floor staff trained in AML typologies or had bill-tracking capabilities installed on slot machines. Both the training content and slot machine technology present in British Columbia gaming facilities would appear to mitigate for this refining typology.

The minimum time investment required should be a consideration when discussing possible money laundering activities and scenarios involving slot machines. The trial 
results presented here provide a baseline estimate to be used going forward when investigating or proposing money laundering methodologies that include slot machines.

\section{Acknowledgments}

The British Columbia Lottery Corporation (BCLC) funded this research in its entirety. BCLC engaged Exiger and its professionals to carry out the testing. The goal of the testing, to empirically determine the time required to process a large amount of cash through slot machines, was determined and communicated by BCLC. The authors independently engaged Carl Schwarz as a statistics consultant, requested documents and information from BCLC, examined the provided information and determined the methodology. BCLC arranged testing sites, days and currency as requested in advance by the authors. BCLC also allowed the authors to review internal and unpublished documentation and training elements relevant to the discussion portion of the article. The authors took the information and feedback provided by BCLC into consideration when drafting the discussion but had final authority over the paper's content. The River Rock Casino and Casino Management provided cash, machines and security for the empirical tests. Exiger's research team members in Vancouver participated as testers.

\section{References}

Cochran, W.G. (1977), Sampling Techniques, Wipubley, New York, NY.

Duhaime, C. (2016), “Casinos \& Money Laundering Q\&A”, Gaming Security Professionals of Canada, available at: http://gspc.ca/wp-content/uploads/2016/08/GSPC-2016-08-15-Casino-ML-QA-Final. pdf (accessed 19 June 2017).

FATF (2016), "Anti-money laundering and counter-terrorist financing measures - Canada”, Fourth Round Mutual Evaluation Report, FATF, Paris, available at: www.fatf-gafi.org/publications/ mutualevaluations/documents/mer-canada-2016.html (accessed 19 June 2017).

FINTRAC (2009), "Money Laundering Typologies and Trends in Canadian Casinos", November, availbale at: www.fintrac-canafe.gc.ca/publications/typologies/2009-11-01-eng.pdf (accessed 1 June 2017).

FINTRAC (2017), Guideline 2: Suspicious Transactions, June, available at: www.fintrac-canafe.gc.ca/ guidance-directives/transaction-operation/Guide2/2-eng.asp (accessed 1 July 2017).

Lee, J. and Shaw, R. (2014), "Despite tougher rules, reports of possible money-laundering up at B.C. casinos", Vancouver Sun. 2014-10-04, available at: www.vancouversun.com/news/ Despite+tougher+rules+reports+possible+money+laundering+casinos/9725744/story.html (accessed 1 June 2017).

North American Industry Classification System (NAICS) (2014), "High Risk/Cash Intensive NAICS Industries", available at: www.naics.com/wp-content/uploads/2014/10/NAICS-ASSOCIATIONHigh-Risk-and-Cash-Intensive-NAICS-Codes-List.pdf (accessed 26 June 2017).

Proceeds of Crime (Money Laundering) and Terrorist Financing Act (PCMLTFA) (2000), Proceeds of Crime (Money Laundering) and Terrorist Financing Act, SC, c. 17), available at: http://canlii.ca/t/ 53004 (accessed 1 July 2017).

Province of British Columbia (2011), "Summary review: anti-money laundering measures at BC gaming facilities", February, available at: www2.gov.bc.ca/assets/gov/sports-recreation-arts-and-culture/ gambling/gambling-in-bc/reports/rpt-pssg-anti-money-laundering-measures-feb-2011.pdf (accessed 26 June 2017).

Smyth, M. (2016), "Smyth: he was paid out more than $\$ 2$ million by B.C. casinos last year, and insists he's just 'lucky", The Province. 2016-04-02, available at: www.theprovince.com/news/ lucky+landscaper+triggers+security+review+casinos/11826265/story.html (accessed 1 June 2017).
Time required to move cash 
JMLC 21,3

\section{Further reading}

BCLC (2017a), "BCLC AML Manual', Unpublished report from British Columbia Lottery Corporation, Kamloops. May 2017, ver. 5.0.

BCLC (2017b), "BCLC Anti-Money Laundering (AML) for Casino and CGC", Unpublished online training from British Columbia Lottery Corporation, Kamloops.

BCLC (2017c), "BCLC Slots Policy: Surveillance Standards Level 1-5”, Unpublished report from British Columbia Lottery Corporation, Kamloops.

\section{About the authors}

Karen Kelly is Director of Strategy and Development at Exiger, a global authority on regulatory compliance. She is based in Exiger's Vancouver office, where she assists on special projects and strategy, primarily related to the immigration, citizenship and visa (ICV) practice. She has significant experience managing and reporting the results of international enhanced due diligence engagements. She is a Certified Anti-Money Laundering Specialist (CAMS) and Certified Associate in Project Management (CAPM). She holds degrees from McGill University (BSc) and Memorial University (BA) and a Graduate Certificate in Intelligence Analysis from the Justice Institute of British Columbia. Karen Kelly is the corresponding author and can be contacted at: kakelly@exiger.com

Carl James Schwarz is a Professor in Statistics and Actuarial Science at Simon Fraser University. His primary research focus is on the development of statistical methodology in capture-recapture studies with secondary research interests in experimental design and survey sampling for environmental impact assessment. He has extensive consulting experience with Federal, Provincial and State agencies and private industry. He is currently a member of the Columbia River Independent Scientific Advisory Board (ISAB) and Independent Scientific Review Panel (ISRP) which reviews all fisheries-related projects on the Columbia River Basin. He holds the PStat (Professional Statistician) designation in both the USA and Canada.

Ricardo Gomez is a Certified Anti-Money Laundering Specialist (CAMS) with over 15 years of experience providing consulting services in the USA, Canada, Latin America and the Caribbean. Ricardo has extensive knowledge of the Bank Secrecy Act ("BSA"), the USA Patriot Act, OFAC regulations and the AML regulatory framework in Latin America and the Caribbean. He specializes in anti-money laundering; investigative due diligence; risk advisory and anti-corruption for clients in the financial, legal and corporate sectors; and non-traditional financial entities concerned with preventing or mitigating money laundering risks. Ricardo Gomez now works for Kaufman Rossin.

Kim Marsh has 35 years of investigative experience for corporate, legal, financial and government clients throughout Canada, Europe, the Middle East, Africa, the Caribbean and Asia. His expertise includes due diligence and bribery investigations, multi-jurisdictional corruption and anti-money laundering. He completed 25 years with the Royal Canadian Mounted Police, retiring as Commander of an International Organized Crime Investigation Unit, where he was responsible for large-scale, covert operations in Europe, Asia and North America. Upon completing his RCMP service in 1998, Kim launched a risk management company that was acquired by IPSA International. While with IPSA, Kim rose to be President of the company and established a globally recognized brand for vetting, governance and training for the citizenship and residence industry. He has lectured internationally to public and private entities on covert investigative practices and multinational money laundering operations. Kim Marsh now works for Marsh Advisory.

For instructions on how to order reprints of this article, please visit our website:

www.emeraldgrouppublishing.com/licensing/reprints.htm

Or contact us for further details: permissions@emeraldinsight.com 